\title{
Nasogastric Tube Feeding Practice and Associated Complication in stroke Patients in a Tertiary Care Hospital in Bangladesh
}

Kazi Mohibur Rahman', Sharif Uddin Khan², ATM Hasibul Hasan', Sirajee Shafiqul Islam, Rajib Nayan Chowdhury ${ }^{5}$, Md. Khairul Kabir Patwary ${ }^{6}$, Dewan Mohammad Elyas, Mohammed Abdul Momen Khan ${ }^{8}$, Md. Amir Hossain 9 , Md. Bakhtiar Azam ${ }^{10}$, Md. Aminul Hasanat ${ }^{11}$

${ }^{1}$ Associate Professor, Department of Interventional Neurology, National Institute of Neurosciences \& Hospital, Dhaka, Bangladesh;

${ }^{2}$ Associate Professor, Department of Neurology, National Institute of Neurosciences \& Hospital, Dhaka, Bangladesh; ${ }^{3}$ Registrar,

Department of Neurology, National Institute of Neurosciences \& Hospital, Dhaka, Bangladesh; ${ }^{4}$ Associate Professor, Department of Interventional Neurology, National Institute of Neurosciences \& Hospital, Dhaka, Bangladesh; ${ }^{5}$ Associate Professor,

Department of Neurophysiology, National Institute of Neurosciences \& Hospital, Dhaka, Bangladesh; ${ }^{6}$ Associate

Professor, Department of Neurology, National Institute of Neurosciences \& Hospital, Dhaka, Bangladesh; ${ }^{7}$ Assistant

Professor, Department of Neurology, National Institute of Neurosciences \& Hospital, Dhaka, Bangladesh;

${ }^{8}$ Assistant Professor, Department of Neurology, National Institute of Neurosciences \& Hospital, Dhaka,

Bangladesh; ${ }^{9}$ Assistant Professor, Department of Neurology, National Institute of Neurosciences \&

Hospital, Dhaka, Bangladesh; ${ }^{10}$ Assistant Professor, Department of Neurology, National Institute of

Neurosciences \& Hospital, Dhaka, Bangladesh; ${ }^{11}$ Assistant Professor, Department of

Anesthesiology, National Institute of Neurosciences \& Hospital, Dhaka, Bangladesh

[Received: 21 January 2017; Revised: 6 March 2017; Accepted: 11 December 2017; Published: 1 January 2018]

\begin{abstract}
Background: Nasogastric tube feeding is an integral part of management of stroke patients with feeding difficulties. Objectives: The purpose of the present study was to evaluate the nasogastric tube feeding practice and its complication on stroke patients. Methodology: One hundred (100) adult patients aged $\geq 18$ years with stroke were enrolled in the study. The diagnosis of stroke was established by the clinical presentation, neuroimaging. Patients requiring nasogastric tube feeding was included in the study. They were thoroughly examined for any complications from possible use of nasogastric tube. Their caregivers were also thoroughly interviewed using a standard preformed questionnaire regarding any complications as well. Results: A total number of 100 patients were recruited for this study. In this study population, $63.0 \%$ patients had ischaemic stroke; $26.0 \%$ had haemorrhagic stroke and $9.0 \%$ population had sub-arachnoid haemorrhage. The most common indication for NG feeding was difficulty in swallowing $(39.0 \%)$ followed by semi consciousness $(26.0 \%)$, unconsciousness $(22.0 \%)$, inability to maintain feed $(10.0 \%)$. About $71.0 \%$ of the patients had complications from NG tube feeding such as nasal irritation $(53.0 \%)$, electrolyte imbalance $(43.0 \%)$, aspiration pneumonia $(40.0 \%)$ and diarrhea (38.0\%). Conclusion: Nasal irritation, aspiration pneumonia, electrolyte imbalance, diarrhea are common complications associated with NG tube feeding which in part may be related to faulty feeding technique. [Journal of National Institute of Neurosciences Bangladesh, 2018;4(1): 23-27]
\end{abstract}

Keywords: Nasogastric tube; feeding practice; complication; stroke patients

Correspondence: Dr. ATM Hasibul Hasan, Registrar (Neurology), National Institute of Neurosciences \& Hospital, Dhaka, Bangladesh; Cell no.: +8801763498663; Email: parag007us@gmail.com

Conflict of Interest: There is no conflict of interest relevant to this paper to disclose.

Funding agency: This research project was not funded by any group or any institution.

Contribution to authors: Rahman KM, Khan SU, Hasan ATMH, Islam SS contributed from the protocol preparation up to report writing. Chowdhury RN, Patwary MKK, Elyas DM involved in the manuscript writing and Khan AM, Hossain MA, Azam B, Hasanat A revised the paper.

How to cite this article: Rahman KM, Khan SU, Hasan ATMH, Islam SS, Chowdhury RN, Patwary MKK, Elyas DM, Khan AM, Hossain MA, Azam MB, Hasanat MA. Nasogastric Tube Feeding Practice and Associated Complication in stroke Patients in a Tertiary Care Hospital in Bangladesh. J Natl Inst Neurosci Bangladesh, 2018;4(1): 23-27

Copyright: (02018. Rahman et al. Published by Journal of National Institute of Neurosciences Bangladesh. This article is published under the Creative Commons CC BY-NC License (https://creativecommons.org/licenses/by-nc/4.0/). This license permits use, distribution and reproduction in any medium, provided the original work is properly cited, and is not used for commercial purposes.

\section{Introduction}

Dysphagia occurs in up to $50 \%$ of patients admitted to hospital with stroke ${ }^{1-4}$. Up to $27 \%$ remain at risk of aspiration by seven days, and up to $8 \%$ have swallowing problems six months after their stroke with $1.7 \%$ still requiring tube feeding ${ }^{5-6}$. Nutritional supplementation can 
reduce mortality in older people at risk of malnutrition, although this has not been shown specifically in the context of stroke ${ }^{7}$. During the period when patients with stroke are unable to take their full dietary requirements normally, the delivery of a liquid feed through a fine bore nasogastric tube is commonly used. The tube is usually secured with adhesive tape around the tube and to the patients face, and is often hooked behind the ear, where more adhesive tape may be used. Unfortunately nasogastric tubes are frequently inadvertently dislodged, due to confusion, restlessness, communication and attention disorders during handling or normal movement. Partial dislodgement may leave the tube misplaced in the lungs, leading to a risk of aspiration. Though, this form of feeding is done mostly by nursing staffs in developed countries, but in our countries it is done solely by people coming along with the patients due to shortage of manpower in public hospitals. Unfortunately most of them cannot comply with standard practice due lack of education, hospital setting, and many other causes. This ultimately leads to adverse hospital outcome of this group of patients due to the complications. Nasopharyngeal discomfort occurs frequently and many suffer sore mouths, thirst, swallowing difficulties, and hoarseness ${ }^{8}$. Short term oesophageal damage can include oesophagitis and ulceration from local abrasion and gastro-oesophageal reflux, occurring in up to $12.5 \%$ of neurological patients 9 . Nausea occurs in $10-20 \%$ of patients and abdominal bloating and cramps from delayed gastric emptying are also common ${ }^{8,9,10}$. Aspiration may occur with no obvious vomiting or coughing, and pneumonia can develop silently. Tube can be easily blocked as well ${ }^{15}$. This study was conducted to see the nasogastric tube feeding practice and its complication in a tertiary care hospital in Bangladesh.

\section{Methodology}

This was an observational type of study conducted in Neurology wards of National Institute of Neurosciences and Hospital from July 2016 to June 2017. The study population included all types of stroke patients aged 18 years above requiring nasogastric feeding tube. The diagnosis of stroke was established by the clinical presentation and neuroimaging (CT scan/ MRI). They were thoroughly examined for any complications from possible use of nasogastric tube. Their caregivers were also thoroughly interviewed using a standard pre formed questionnaire regarding any complications as well. Semi-structured questionnaires were formed that include all the variables of interest. This questionnaire was used for collection of information by interviewing patients. The questions were designed to elicit details of the use of nasogastric feeding, its associated complications ad possible underlying factors of these complications. No data or any information was collected without permission of the participant. Participation in this study was completely voluntary. Written informed consent was taken from each patient. Prior to consent they were explained the aim and purpose of the study. Confidentiality was assured and anonymity was maintained; no participants were identified in any report or publication under this study. The data was analyzed using SPSS version 19.0. The results were presented in tables and graphs. Chi-square test was performed and compared at 5\% level of significance $(p<0.05)$.

\section{Results}

This study included 100 patients of stroke requiring nasogastric feeding tube. More than half of our study patients belonged to 51 to 60 years age group $(53.0 \%)$, followed by $38.0 \%$ in 61 to 70 years and only $5.0 \%$ were elder than 70 years. Majority of them were male $(69.0 \%)$ (Table 1).

Table 1: Socio-Demographic Characteristics of the Respondents $(\mathrm{n}=100)$

\begin{tabular}{lcc}
\hline Variables & Frequency & Percent \\
\hline Age Group & & \\
$<50$ Years & 4 & $4.0 \%$ \\
51 to 60 Years & 53 & $53.0 \%$ \\
61-70 Years & 38 & $38.0 \%$ \\
$>70$ Years & 5 & $5.0 \%$ \\
Gender & & \\
Male & 69 & $69.0 \%$ \\
Female & 31 & $31.0 \%$ \\
\hline
\end{tabular}

In this study, $63.0 \%$ patients had ischaemic stroke, $28.0 \%$ had haemorrhagic stroke and $9.0 \%$ had subarachnoid haemorrhage (Figure I).

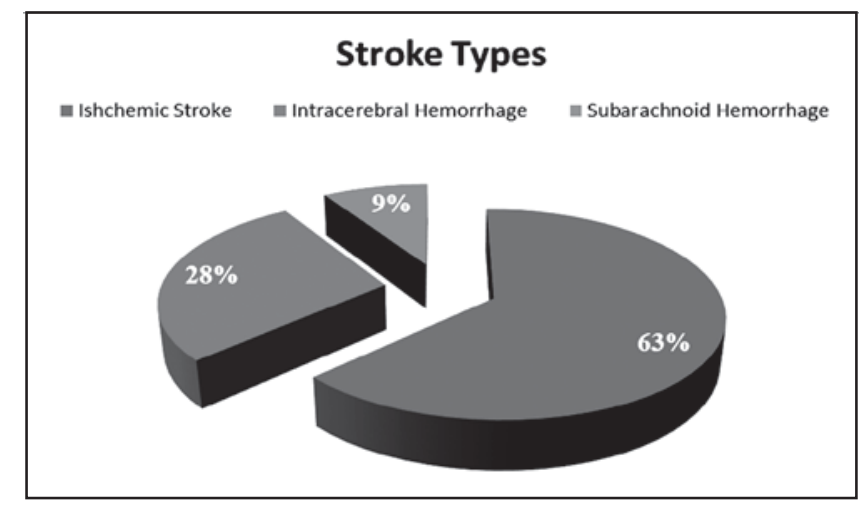

Figure I: Distribution types of Stroke 
Hypertension was most common risk factor of stroke ( $88 \%$ in hemorrhagic stroke and $85.71 \%$ with ischemic stroke) followed by smoking ( $49 \%$ and $65 \%$ ), diabetes mellitus (24\% and 26.25\%), Dyslipidaemia (30\%, $35 \%$ ) in (Table 2).

Table 2: Distribution of Risk Factors in Different Types of Stroke $(\mathrm{n}=100)$

\begin{tabular}{lcc}
\hline Risk Factors & Haemorrhage & Infarction \\
\hline HTN & $28(88 \%)$ & $56(85.71 \%)$ \\
Smoking & $18(49.14 \%)$ & $41(65 \%)$ \\
Diabetes & $9(24 \%)$ & $16(25.39 \%)$ \\
Dyslipidaemia & $13(35 \%)$ & $19(30.15 \%)$ \\
IHD & $11(29 \%)$ & $15(23.8 \%)$ \\
H/O TIA, CVD & $1(2.8 \%)$ & $3(4.76 \%)$ \\
Drugs(OCP) & 0 & 3 \\
\hline
\end{tabular}

Difficulty in swallowing (39\%) was the most common indication for nasogastric tube insertion followed by altered level of consciousness in $25 \%$. About $10 \%$ of patients were unable to maintain their adequate feeding despite being able to eat orally and given NG tube (Figure II).

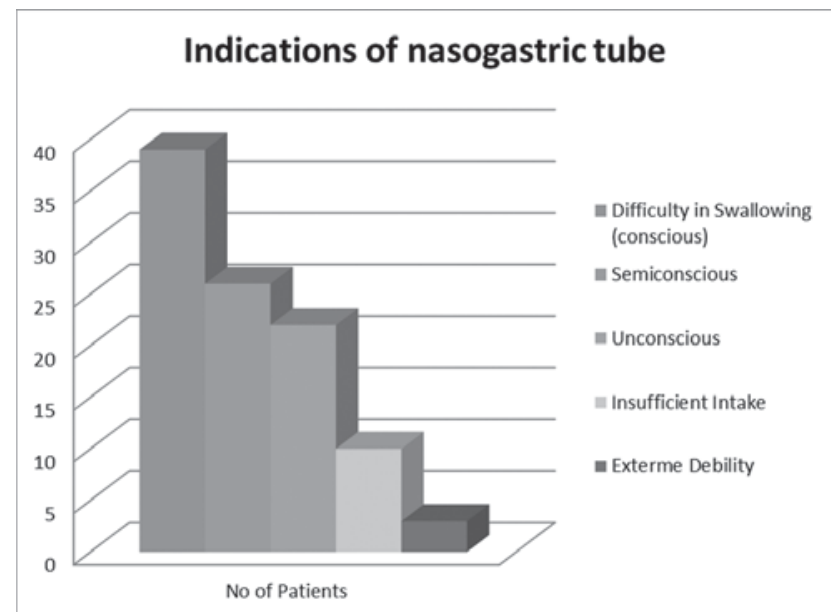

Figure II: Indications of Use of Nasogastric tube in Various Stroke Patients

Among the 100 patients studied, 71 had complications attributed to NG tube feeding. The most common complication was nasal irritation (38) and tube blockage (38) followed by electrolyte imbalance (31), aspiration pneumonia (29), Diarrhoea (27). Thirty one patients had tube displacement at some point of time and 13 patients were malnourished due to inadequate feeding. Some patients had more than one complication at the same time.
In comparison, of the 29 patients who developed aspiration pneumonia, $13(44.0 \%)$ was suffering from ischaemic stroke, $16(55.0 \%)$ was suffering from haemorrhagic stroke. Twenty four $(63.0 \%)$ of the patients who reported nasal irritation was suffering from ischaemic stroke, 14(36.84\%) was suffering from haemorrhagic stroke. Diarrhoea was reported by both ischaemic stroke $(55.0 \%)$ and haemorrhagic stroke $(44.4 \%)$ patients. Electrolyte imbalance was found in both ischaemic stroke (45.16\%) and haemorrhagic stroke $(54.83 \%)$ patients. Tube blockage was reported more in haemorrhagic group $(52.63 \%)$ than the other group $(47.37 \%)$. Tube displacement was experienced by both group of patients $(45.0 \%$ and $54.0 \%$ respectively). Malnutrition was found in both group of patients $(53.0 \%$ in ischaemic stroke, $46.0 \%$ in haemorrhagic stroke) (Table 3).

Table 3: Comparison between Complications and type of stroke $(n=71)$

\begin{tabular}{lcc}
\hline $\begin{array}{l}\text { Type of } \\
\text { Complication }\end{array}$ & $\begin{array}{c}\text { Ischaemic } \\
\text { Stroke }\end{array}$ & $\begin{array}{c}\text { Haemorrhagic } \\
\text { Stroke }\end{array}$ \\
\hline Aspiration Pneumonia & $13(44 \%)$ & $16(55 \%)$ \\
Nasal Irritation & $24(63 \%)$ & $14(36.84)$ \\
Diarrhoea & $15(55.5 \%)$ & $12(44.4 \%)$ \\
Electrolyte Imbalance & $14(45.16 \%)$ & $17(54.83 \%)$ \\
Tube Blockage & $18(47.37 \%)$ & $20(52.63 \%)$ \\
Tube Displacement & $14(45.16 \%)$ & $17(54.83 \%)$ \\
Malnutrition & $7(53.84 \%)$ & $6(46.15 \%)$ \\
\hline
\end{tabular}

\section{Discussion}

Stroke is a common medical emergency. Stroke patients make up a major bulk of admission in most tertiary hospitals. Under nutrition is a common problem and is poorly recognized in hospital setting. It has been seen that $1 / 3$ of patients are affected by moderate or severe malnutrition on admission and elderly are particularly at greater risk ${ }^{11}$. Underlying causes leading to poor nutritional intake are many which includes reduced conscious level, an unsafe swallow, arm or facial weakness, poor mobility and ill fitting dentures. Malnutrition in acute stroke is associated with increased prevalence of complication, impaired immunologic function and a higher mortality rate $^{12}$. Appropriate nutritional support reduces complications and mortality in stroke patients. Due to the high burden of patients and lack of manpower, the patients requiring artificial feeding is a neglected field. Majority of these patients are incapable to take food orally and require NG tube feeding. In this study, complications 
associated with NG tube feeding in stroke patients were evaluated.

This study comprised of 100 patients with different types of stroke who required NG tube for feeding purpose. A study by Hussain et al showed that Most of the patients suffering from stroke were male $(74 \%)$ and most of them were between 51 to 70 years of age (69.0\%) which correlates to this study finding although another study done in $\mathrm{DMCH}$ among young stroke patients show slightly higher percentage (M: F 52:47) regarding sex distribution. This might be related to age of the subjects as many factors influence stroke in different age group ${ }^{13,14}$. The distribution of stroke types were also similar to the study conducted by Hussain et al where ischaemic stroke was $61 \%$, haemorrhagic stroke was $39.0 \%$. Higher rate of haemorrhagic stroke is also have been reported in number of hospitals in Asian countries such as Singapore, Malaysia (33\%), Thailand (30\%), Korea (31\%), Taiwan $(31 \%)^{15}$.

In this study hypertension was the most important risk factor of stroke, followed by smoking and diabetes mellitus, dyslipidaemia. Two previous Bangladeshi studies conducted by Siddique et al and Hossain also describes similar findings ${ }^{14,16}$.

In a study done by Miah et al, reported that $78 \%$ of the stroke patients' required NG tube feeding for stroke ${ }^{17}$. Indications for NG tube feeding were analyzed in our study population. The most common indication for NG tube feeding was dysphagia (39\%). It has been reported that dysphagia can occur up to $50 \%$ of patients following stroke ${ }^{1-4}$. In a study by Miah et al, $24.0 \%$ was fed via NG tube for dysphagia ${ }^{17}$. In our study, total $48.0 \%$ of the patients required NG tube feeding for alteration of consciousness which is comparable to the results of Miah et $\mathrm{al}^{17}$. In this study, $10.0 \%$ of the patients were given NG tube feeding due to poor intake and 3\% due extreme debility. Patients who are capable of swallowing liquids and food may have a poor appetite because of the effects of inter current illness or medication and they may eat more slowly or be less keen to eat because of facial weakness, lack of dentures or poor arm function ${ }^{18}$. In a Bangladeshi study it has been reported that this cause to be $22.0 \%$ which is comparable to this present study ${ }^{17}$.

Out the 100 patients studied, 71 patients had complications. Nasal irritation was reported by $38(53.0 \%)$ of patients. Among the complications studied in western countries, following NG tube insertion, nasal irritation is one of the more common one and it is more prevalent in those requiring large bore ones ${ }^{19}$. The second most common complication was aspiration pneumonia in our patients which was found in $29(40.0 \%)$ of patients. A western study found that up to $27.0 \%$ remain at risk of aspiration by seven days. Our results show a higher percentage. Possible reasons might be due to the fact that the whole feeding process is done in our setting by untrained persons ${ }^{5}$. Gastro-oesophageal reflux occurs frequently with NG tube feeding. It is more common when patients are NG fed in the supine position and reflects a combination of gravitational back flow and impairment of gastro-oesophageal sphincter function induced by pharyngeal stimulation and the presence of the tube across the cardia. It is very common in patients with impaired consciousness or poor gag reflexes, occurring in up to $30.0 \%$ of those with tracheostomies and $12.5 \%$ of neurological patients ${ }^{16-18}$.

Aspiration may occur with no obvious vomiting or coughing, and pneumonia can develop silently. Electrolyte imbalance was found in 31(43.0\%) patients. The actual reason behind the electrolyte imbalance may be multifactorial. One of the contributing factors might have been the diarrhoea. Other underlying factors might be over hydration due to supplementary IV fluids, excess loss due to drugs or syndrome of inadequate $\mathrm{ADH}$ secretion or cerebral salt wasting syndrome as a result of the stroke itself. One of the underlying mechanisms contributing to the electrolyte imbalance has been attributed to re-feeding syndrome. In this case the sudden onset of artificial nutritional support appears to reverse the above processes and along with insulin driven movements of electrolytes into cells, can lead to precipitous falls in circulating levels of potassium, magnesium, calcium, and phosphate. There may also be an accompanying acute increase in circulating and extracellular fluid due to exogenous administration, the endogenous movement of sodium and water out of cells, and the diminished ability of undernourished kidneys to excrete a salt and water load ${ }^{11}$. In this study $31(43.0 \%)$ patients had tube displacement at some point of time and required tube reintroduction. It correlates to the fact that approximately $25.0 \%$ of nasogastric tubes fall out or are pulled out by patients soon after insertion and tubes, especially those that are fine bore, can be displaced by coughing or vomiting ${ }^{16}$. Thirteen $(18.0 \%)$ patients were malnourished due to inadequate feeding. It has been related to eating problems, age, poor nutritional status on admission and immobilization in patients with impaired functional capacity. A study in $\mathrm{DMCH}$ regarding the feeding practice showed that almost all the patients requiring NG feeding for stroke 
were being given foods with substandard calorie which may explain the malnutrition in our stroke patients ${ }^{19-21}$. The result of the present study should be considered in light of the following limitations. First the sample size was relatively small and the period of time of the study was short. Second, the study was a hospital based study in the capital city, so the result may not reflect the actual epidemiological and clinical picture.

\section{Conclusion}

The present study provides information regarding the various complications that arise as a result of NG tube feeding in stroke patients. NG tube feeding is an important part of managing the nutritional part of these patients. But unfortunately it is neglected as well. This study highlights the fact that a very high percentage of NG tube fed patients developed various complications.

\section{References}

1. Gordon C, Langton-Hewer R, Wade D. Dysphagia in acute stroke. Br Med J 1987; 295:411-414

2. Wolfe C, Taub N, Woodrow J, Richardson E, Warburton F, Burney P: Patterns of acute stroke care in three districts of southern England. J Epidemiology Comm Health 1993; 47:144-8

3. Odderson IR, Keaton JC, McKenna BS: Swallow management in patients on an acute stroke pathway: quality is cost effective. Arch Phys Med Rehabil 1995; 76:1130-1133

4. Barer D: The natural history and functional consequences of dysphagia after hemisphere stroke. J Neurol Neurosurg Psych $1989 ; 52: 236-241$

5. Smithard DG, O'Neill PA, England RE, Park CL, Wyatt R, Martin DF, Morris J. The Natural History of Dysphagia following a Stroke. Dysphagia 1997; 12(4):188-193

6. Elia M, Stratton RJ, Holden C, Meadows N, Micklewright A, Russell C, Scott D, Thomas A, Shaffer J, Wheatley C, Woods S: Committee of the British Artificial Nutrition Survey (BANS) . Home Enteral feeding after Cerebrovascular Accident. Clinical Nutrition 2001; 20(1):27-30
7. Milne AC, P J, Avenell A: Protein and energy supplementation in elderly people at risk from malnutrition, in The Cochrane Database of Systematic Reviews: Reviews 2005. John Wiley \& Sons Ltd, Chichester, UK; 2005

8. Duncan HD, Silk DB. Problems of treatment - enteral nutrition. In: Nightingale J, ed. Intestinal failure. London: Greenwich Medical Media Ltd, 2001:477-96

9. Winterbauer RH, Duming RB, Barron E, et al. Aspirated nasogastric feeding solution detected by glucose strips. Ann Intern Med 1981; 95:67-8

10. Bury KD, Jambunathan G. Effects of elemental diets on gastric emptying and gastric secretion in man. Am J Surg 1974;127:59-66 11. Albiin N, Asplund K, Bjermer L. Nutritional status of medical patients on emergency admission to hospital. Acta Med Scand 1982; 212: 151-156

12. Dominioni L, Dionigi R. Immunological function and nutritional assessment. J Parenter Enteral Nutr 1987;11:70-72

13. AM Hossain, NU Ahmed, M Rahman, MR Islam, G Sadhya, K Fatema. Analysis of Sociodemographic and Clinical Factors Associated with Hospitalized Stroke Patients of Bangladesh. Faridpur Med Coll J 2011; 6(1):19-23

14. Hossain MZ, Ahmed SU, Sarder MH, Dasgupta R, Das A et al. Analysis of Risk Factors Associated with Stroke in young Adults : A Prospective Study. J Dhaka Med Coll. 2009;18(2):95-100

15. Wong KS. International prospective hospital-based study of acute stroke incidence. Lancet 1998;352

16. Siddique AN, Nur Z, MD. Mahbub S, Alam B, Miah M T. Clinical Presentation and Epidemiology of Stroke - A study of 100 Cases. J Medicine 2009;10:86-89

17. Miah MT, Amin MA, Khan MAI et al. Feeding practice in acute stroke patients in a tertiary care hospital. Bangladesh Med Res Counc Bull 2010; 36: 78 -81

18. Sriram K, Jayanthi V, Lakshmi RG, et al. Prophylactic locking of enteral feeding tubes with pancreatic enzymes. JPEN J Parenter Enteral Nutr 1997;21:353-5

19. Onosson M, Ek AC, Bjurulf $\mathrm{P}$, et al. Feeding dependence and nutritional status after acute stroke. Stroke 1994; 25 : 366-71

20. Axelsson K, Asplund K, Norberg A, Alafuzoff I. Nutritional status in patients with acute stroke. Acta Med Scand 1988; 224:217-24

21. Gariballa SE, Parker SG, Taub N, Castleden CM. Influence of nutritional status on clinical outcome after stroke. Am J Clin Nutr 1998; 68: 275-81 